\title{
MEASUREMENT AND MODELING OF THE INFLUENCE OF GRAIN SIZE AND PRESSURE GRADIENTS ON SWASH ZONE SEDIMENT TRANSPORT
}

\begin{abstract}
Ilya K. Othman ${ }^{1 ., 2}$, Tom E. Baldock ${ }^{1}$, David P. Callaghan ${ }^{1 .}$
The paper examines the dependency between sediment transport rate, $q$, and grain size, $D$, (i.e. $q \propto D^{p}$ ) in the swash zone. Experiments were performed using a dam break flow as a proxy for swash overtopping on a mobile sediment beach. The magnitude and nature of the dependency (i.e. $p$ value) is inferred for different flow parameters; the initial dam depth (or initial bore height), $d_{o}$, the integrated depth averaged velocity, $\int \bar{u}^{3} d t$, and against the predicted transport, $q_{p}$, using the Meyer-Peter Muller (MPM) transport model. Experiments were performed over both upward sloping beds and a horizontal bed. The data show that negative dependencies $(p<0)$ are obtained for $d_{o}$ and $q_{p}$, while positive dependencies $(p>0)$ are obtained for $\int \bar{u}^{3} d t$. This indicates that a given $d_{o}$ and $q_{p}$ transport less sediment as grain size increases, whereas transport increases with grain size for a given $\int \bar{u}^{3} d t$. The $p$ value is expected to be narrow ranged, $0.5 \leq p \leq-0.5$. A discernible difference observed between the measured and predicted transport on horizontal and sloping beds suggests different modes of transport. The incorporation of a pressure gradient correction, $d p / d x$, using the surface water slope (i.e. piezometric head), in the transport calculation greatly improved the transport predictions on the horizontal bed, where $d p / d x$ is positive. On average, the incorporation of a pressure gradient term into the MPM formulation reduces $q_{p}$ in the uprush by $4 \%$ (fine sand) to $18 \%$ (coarse sand) and increases $q_{p}$ over a horizontal bed by $1 \%$ (fine sand) to two orders of magnitude (coarse sand). The measured transport for fine and coarse sand are better predicted using MPM and MPM $+d p / d x$ respectively. Poor predictions are obtained using Nielsen (2002) because the pressure gradient in the uprush is of opposite sign to that inferred from velocity data in that paper. It is suggested that future swash sediment transport models should incorporate the grain size effect, partly through the pressure gradient, although the $d p / d x$ influence is small for fine sands because of the grain size scaling contained in the stress term.
\end{abstract}

Keywords: sediment transport; swash; dam break; uprush; grain size

\section{INTRODUCTION}

Sand and shingle beaches exhibit grain sizes that vary by approximately two orders of magnitude, between $D_{50}=0.15 \mathrm{~mm}$ and $20 \mathrm{~mm}$. Extensive steady flow sediment transport data with different grain sizes exists, with more limited oscillatory wave data taken for sandy beaches with medium grain sizes up to $0.5 \mathrm{~mm}$ (e.g. O'Donoghue and Wright, 2004). There is no experimental data that explicitly considers the influence of grain size on swash zone sediment transport, albeit with wide acceptance that grain size influences beach morphology and the morphodynamics response (van Rijn et al., 2007). While run up and overtopping in the swash zone is reasonably represented as a one dimensional flow, no clear theory has emerged to explain how transport rate and grain size are related (i.e. $q \propto D^{p}$, where $q$ is transport rate and $D$ is a measure of grain size) in the swash zone. Even for the simpler steady flows, there is no consensus as to the influence of grain size on transport rate, with disagreement found across the riverine-sediment transport literature (Martin and Church, 2000). The $q-D$ correlation was originally introduced empirically by Bagnold $(1980,1986)$ using an inhomogeneous formula (i.e. unbalanced dimensions). However, a contradiction exists between Bagnold's (1956) theory and his (1986, 1980) empirical correlations. The former support the Meyer-Peter Muller (MPM) transport relationship, with an additional constant dependent on $\mathrm{D}$, but the latter demonstrated an inverse dependency, $q_{b} \propto D^{-1 / 2}$.

The current transport models, largely derived from steady flow based on the Shields (1936) approach in terms of bed shear stress, have a positive dependency on grain size solely through the friction factor. Additionally, the widely applied CERC formula for longshore transport is also independent of grain size and field/laboratory data (e.g. Del Valle et al., 1993) show a weak negative dependency.

Owing to the uncertainty in the $q-D$ dependency, the present study examined the dependency experimentally for a range of different parameters. The $p$ values are inferred for different flow parameters; the initial dam depth (or initial bore height), $d_{o}$, the integrated depth averaged velocity, $u^{3}$, and the predicted transport, $q_{p}$, using the Meyer-Peter Muller (1948) transport model.

\section{METHOD}

Novel and idealized experiments simulating swash uprush and overtopping on a mobile sediment beach were conducted using a tilting dam break apparatus (Figure 1). Results for two grain sizes,

\footnotetext{
1. School of Civil Engineering, University of Queensland, St Lucia, Brisbane, Queensland, 4072, Australia.

2. Faculty of Civil Engineering, Universiti Teknologi Malaysia, Skudai, Johor, 81310, Malaysia.
} 
$D_{50}=0.22 \mathrm{~mm}$ and $2.65 \mathrm{~mm}$, and a range of beach slopes, $\tan \beta=1 / 10,1 / 20,1 / 30$ and 0 (positive value of $\beta$ refers to upsloping beds) are presented here. The gate opening was performed manually and video analysis showed that the gate was fully opened to a height $>0.2 \mathrm{~m}$ in less than $0.12 \mathrm{~s}$ (Barnes, 2009), hence the opening can be considered as nearly instantaneous. The reservoir lengths were kept constant at $1 \mathrm{~m}$ and the flow depths were measured at $0.535 \mathrm{~m}, 1.235 \mathrm{~m}, 1.635 \mathrm{~m}, 1.775 \mathrm{~m}$ and $1.955 \mathrm{~m}$ downstream of the gate and sampled at $50 \mathrm{~Hz}$ using ultrasonic displacement sensors. Careful consideration is given to the intersection between the sand and the gate to minimize significant scour once the gate is lifted and piping action from water leaking from the gate. Prior to each run, the water in front of the gate is kept dry using a pump and a $0.5 \mathrm{~cm}$ diameter drain hole to ensure a "dry" but saturated downstream bed. The sand bed is leveled manually to its initial thickness of $2 \mathrm{~cm}$ between runs. The experiments provide highly reproducible measurements with low free-stream turbulence intensity, removing the complication of pre-suspended sediment. The total transport, $q_{m}$, is measured by trapping the overtopped sediment, capturing bed load and suspended sediment (Baldock et al., 2005).

It is well known that the moving shoreline (i.e. wetting and drying) leads to missing data collection at the peak velocity during the start of the uprush and at the end of the backwash, as previously encountered in many laboratory (Barnes and Baldock, 2007, O'Donoghue et al., 2010) and field studies (Blenkinsopp et al., 2010, Masselink and Russell, 2006). This period of the flow transports a significant amount of sediment. Hence, due to the difficulties in obtaining the full duration of swash velocities, the present study used the depth averaged velocity, predicted using a finite volume model, TUFLOWfv, calibrated against the measured flow depth, overtopping volume, and wave tip celerity. Herein, all calculations are performed using the calibrated velocities unless otherwise stated. Additionally, measured velocities are subject to boundary layer effects, hence the depth average velocity from the model is preferred as representative of the real flow velocity. Note that the velocity scale in this study is approximately 1 to $1 / 3$, where the maximum depth averaged velocity on horizontal bed reached $\approx$ $1.4 \mathrm{~m} / \mathrm{s}$ in comparison to the actual swash run up velocity measured on the beach of $\approx 4 \mathrm{~m} / \mathrm{s}$ (Baldock and Hughes, 2006, Hughes and Baldock, 2004, Elfrink and Baldock, 2002).

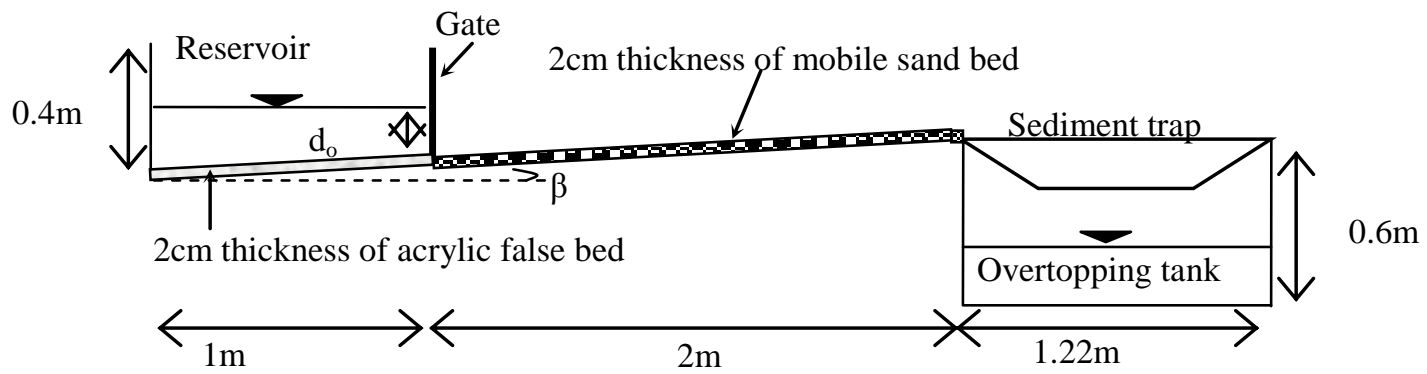

Figure 1. Experimental setup.

\section{RESULTS}

\section{Grain size dependency}

For a given forcing parameter, if $q$ is assumed as a function of $D$ only (i.e. $q \approx D^{p}$ ), the dependency can be deduced following (King, 2005):

$$
p=\frac{\log \left(q_{1} / q_{2}\right)}{\log \left(D_{1} / D_{2}\right)}
$$

where $q_{1} / q_{2}$ is the ratio of $q$ from the smaller grain size divided by $q$ from the larger grain size and $D_{1}<D_{2}$. The values of $q$ are obtained from the slope of the linear fit regression lines from data covering a range of flow rates. To date, there is no definite formula to calculate $p$ and the current approach gives a simple relationship. Alternatively, Equation (1) can be used by comparing $q_{1}$ and $q_{2}$ under similar flow condition (i.e. $\theta_{1}=\theta_{2}$ ) (King, 2005). However, for unsteady flow, $\theta$ is not constant over the duration of each test. Hence, the dependencies are inferred using the initial dam depth (or initial bore height), $d_{o}$, time integrated depth average velocity, $\int \bar{u}^{3} d t$, and time integrated predicted transport, $q_{p}$, using Meyer-Peter Muller (1948) transport model. 


\section{Total transport versus initial reservoir depth}

The initial depth of the reservoir, $d_{o}$ can be interpreted as a measure of the initial bore strength when the water is released from the static condition, causing the potential energy to be converted to kinetic energy, driven by a strong initial pressure gradient, $d p / d x$.

Taking the initial depth, $d_{o}$, as the controlling parameter, Figure 2 shows an inverse $q-D$ relationship in which sediment transport increases with a decrease in grain sizes (i.e. negative $p$ ). The negative dependency for $d_{o}$ is expected from frictional effects, represented by the velocity feedback as indicated by the modeled velocity (i.e. Figure 8 and Figure 10). The maximum calculated $p$ values of 0.22 and -0.19 are attained on $\tan \beta=1 / 20$ and the horizontal bed, respectively. The linear regression equations and the associated $R^{2}$ are specified in Table 1 .
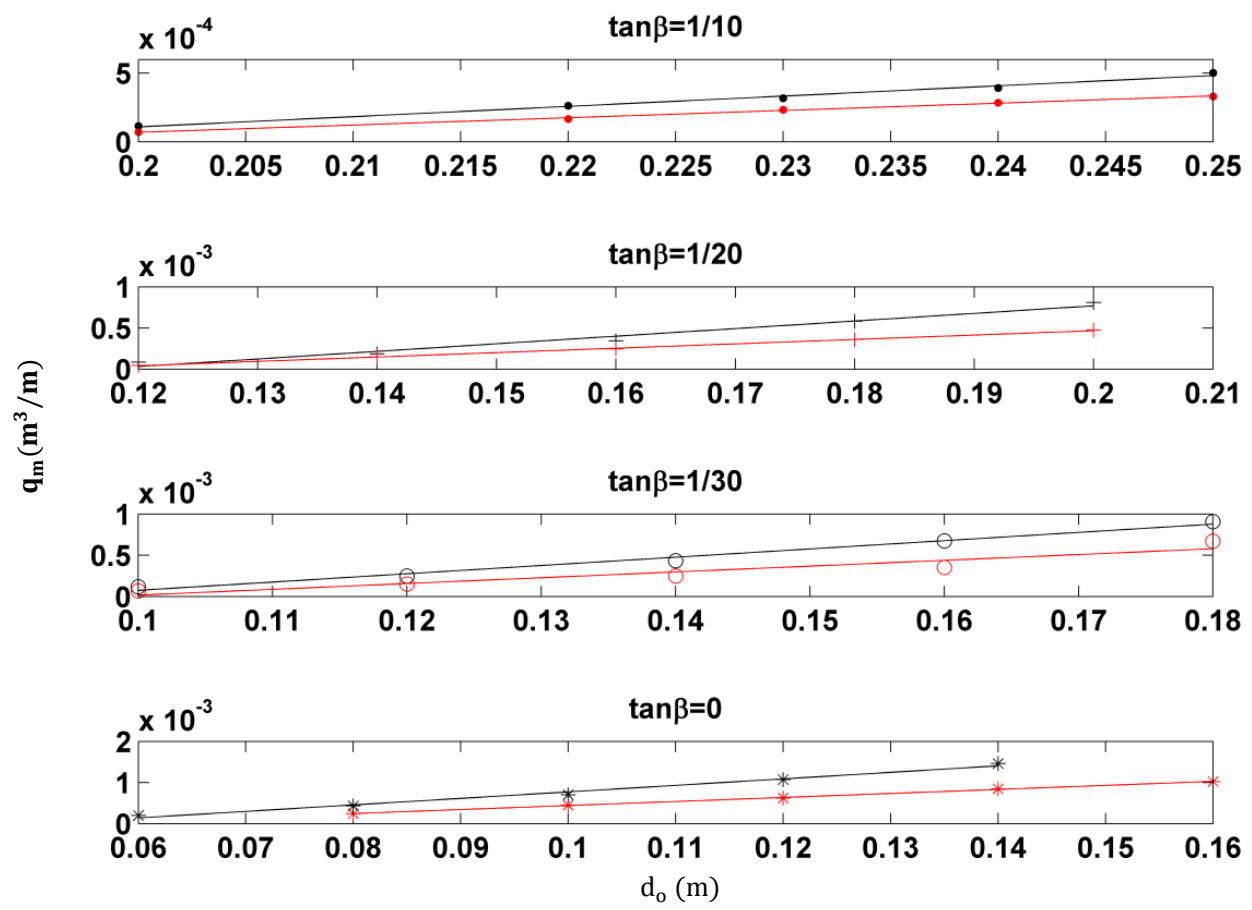

Figure 2. Measured transport, $q_{m}$, against $q_{p}$ for $D_{50}=0.22 \mathrm{~mm}$ (black) and $2.65 \mathrm{~mm}$ (red).

\begin{tabular}{|l|l|l|}
\hline \multicolumn{3}{|c|}{ Table 1. Linear regression for $\boldsymbol{d}_{\boldsymbol{o}}$. } \\
\hline $\tan \beta$ & Linear regression equation, $y=; R^{2}$ \\
\cline { 2 - 3 } & $D_{50}=0.22 \mathrm{~mm}$ & $D_{50}=2.65 \mathrm{~mm}$ \\
\hline $1 / 10$ & $0.0075 x-0.0014 ; 0.99$ & $0.0053 x-0.001 ; 1$ \\
$1 / 20$ & $0.0092 x-0.0011 ; 0.98$ & $0.0053 x-0.0006 ; 1$ \\
$1 / 30$ & $0.01 x-0.0009 ; 0.99$ & $0.007 x-0.0007 ; 0.90$ \\
0 & $0.0158 x-0.0008 ; 0.99$ & $0.0098 x-0.0005 ; 1$ \\
\hline
\end{tabular}

Total transport versus $U^{3}$

Unlike the usual oscillatory data, the present dam break swash does not have the root mean square value of current velocity, $\tilde{u}$, that is usually used in the literature (e.g Ribberink and Al-Salem, 1995) to relate the measured transport and velocity. Hence, $\int \bar{u}^{3} d t$ is inferred as a sum of the depth averaged instantaneous velocity from the start of the flow until $\bar{u}>u_{c r}$ (i.e. $\int_{t=u_{\max }}^{t=u>u_{c r}} \bar{u}^{3} d t$ ), where $u_{c r}=$ $\sqrt{(s-1) g D \theta_{c r}}, s=2.65, g=9.81 \mathrm{~m} / \mathrm{s}^{2}$ and $\theta_{c r}$ are critical velocity, specific gravity of sand, gravity, and critical Shield's parameter respectively. The values of $\theta_{c r}$ used in the calculation are discussed below and summarized in Table 3 .

The data in Figure 3 demonstrate a linear relationship with $\int \bar{u}^{3} d t$ and increasing transport at larger $D_{50}$ for a given $\int \bar{u}^{3} d t$, in contrast to the relationship with $d_{o}$. This is associated with the monotonically decreasing velocity and reduced overtopping duration as $D_{50}$ increases. The linear regression equations and the associated $R^{2}$ are given in Table 2 and the calculated $p$ values range from 0.13 to 0.2 . 


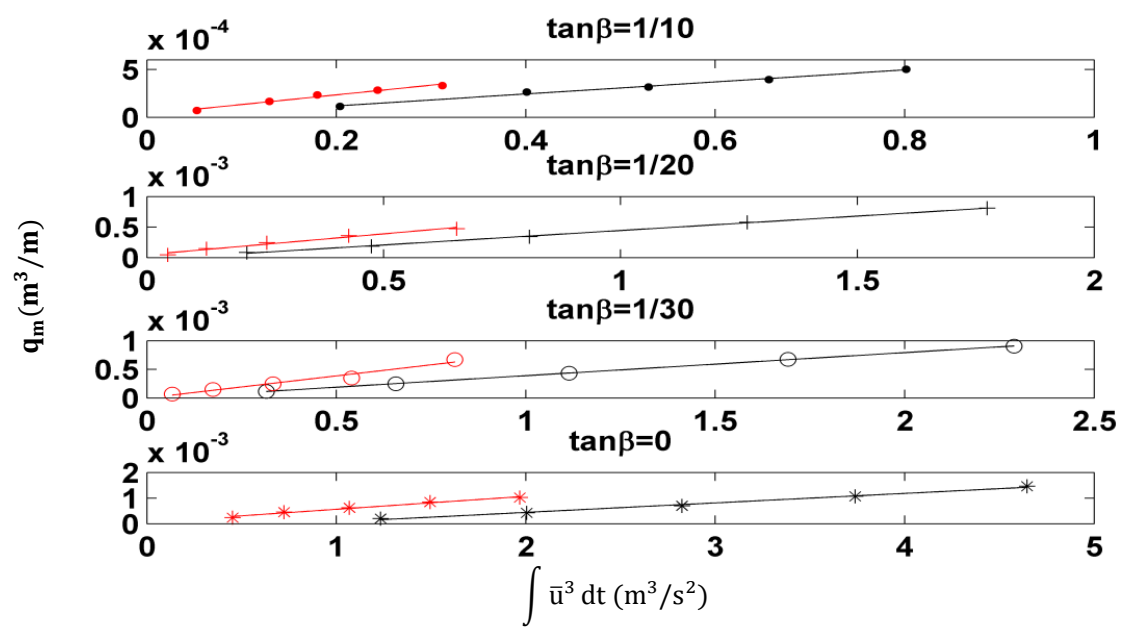

Figure 3. Measured transport, $q_{m}$, against $\int \bar{u}^{3} d t$ for $D_{50}=0.22 \mathrm{~mm}$ (black) and $2.65 \mathrm{~mm}$ (red).

\begin{tabular}{|l|l|l|}
\hline \multicolumn{3}{|c|}{ Table 2. Linear regression for $\int \overline{\boldsymbol{u}}^{3} \boldsymbol{d t}$. } \\
\hline $\tan \beta$ & \multicolumn{2}{|c|}{ Linear regression equation, $y=; R^{2}$} \\
\cline { 2 - 3 } & $D_{50}=0.22 \mathrm{~mm}$ & $D_{50}=2.65 \mathrm{~mm}$ \\
\hline $1 / 10$ & $0.0006 x ; 0.99$ & $0.001 x ; 0.98$ \\
$1 / 20$ & $0.0005 x ; 1$ & $0.0007 x ; 0.98$ \\
$1 / 30$ & $0.0004 x ; 1$ & $0.0008 x ; 0.97$ \\
0 & $0.0004 x-0.0003 ; 0.99$ & $0.0005 x ; 0.99$ \\
\hline
\end{tabular}

\section{Measured transport versus predicted transport}

The predicted transport, $q_{p}$, calculated in this section includes a critical slope correction, $\theta_{c r}$, to account for the threshold of motion for a particle on a slope, where particles on a downward slope will be easily more dislodged and vice versa. $\theta_{c r}$ is given below, derived from a force balance in air via the Coulomb Law as explained and proposed by (Fredsoe and Deigaard, 1992).

$$
\theta_{c r}=\theta_{c r \beta=0}\left(1 \pm \frac{\tan \beta}{\tan \alpha}\right) \cos \beta
$$

where $\tan \beta$ and $\tan \alpha=0.63\left(\alpha=32.2^{\circ}\right)$ are the bed slope and angle of repose of sediment, respectively. Although tan $\alpha$ should physically vary with sediment properties (size, shapes, angularity, packing density) and condition (degree of saturation, immersed or dry) (Friedman and Robinson, 2002, Carrigy, 1970), no analytical formulation exists that links all these properties and conditions to $\alpha$. For example, experimental studies of Miller and Byrne (1966, Table I, pg 307) and Carrigy (1970, Table V, pg157) show that average $\alpha$ for quartz sand is around $35^{\circ}$ and increases by an order of $1 \%$ for sand submerged in water.

Alternatively, the experimental studies of Bagnold (1956) have suggested that $\tan \alpha$ varies from 0.32 (large grains) to 0.75 (small grains) depending on whether the flow regime is viscous or inertial. The flow regime is given as a function of sediment concentration which is not being measured for the present study. Owing to these difficulties, the default value of 0.63 is used. The critical Shield's value on a horizontal bed, $\theta_{c r \beta=0}$, is estimated from the Shield's diagram, following the proposed formulae of (Van Rijn, 1993):

$$
\theta_{c r \beta=0}=\left\{\begin{array}{cc}
0.14 D_{*}^{-0.64}, & 4<D_{*} \leq 10 \\
0.013 D_{*}^{0.29}, & 20<D_{*} \leq 150
\end{array}\right.
$$

where $D_{*}=\left[g(s-1) / v^{2}\right]^{1 / 3} D_{50}$ and $v=10^{-6} \mathrm{~m}^{2} / \mathrm{s}$ are dimensionless grain size and kinematic viscosity of water at $20^{\circ} \mathrm{C}$, respectively.

The inclusion of the slope correction increases $\theta_{c r}$ for the uprush by approximately $15 \%, 8 \%$ and $5 \%$ for $\tan \beta=1 / 10,1 / 20$ and $1 / 30$ correspondingly, compared to the horizontal bed value. $\theta_{c r}$ values used in the calculations are summarized in Table 3. Additionally, it is worth pointing out that Equation (2) for the critical slope correction has been wrongly applied as a correction to $\theta$ in some of the sediment transport literature. 


\begin{tabular}{|l|l|l|l|l|}
\hline \multicolumn{5}{|c|}{ Table 3. Values of $\boldsymbol{\theta}_{c r}$ used in transport calculations. } \\
\hline$D_{50}(\mathrm{~mm})$ & $D_{*}(-)$ & $\theta_{c r \beta=0}$ & $\tan \beta$ & $\theta_{c r}$ Uprush \\
& & & & \\
\hline 0.22 & 5.51 & 0.047 & $1 / 10$ & 0.0542 \\
& & & $1 / 20$ & 0.0507 \\
& & & $1 / 30$ & 0.0495 \\
\hline 2.65 & 66.33 & 0.044 & $1 / 10$ & 0.0507 \\
& & & $1 / 20$ & 0.0474 \\
& & & $1 / 30$ & 0.0463 \\
\hline
\end{tabular}

The subsequent sections present the transport predictions using: MPM; MPM with the inclusion of $d p / d x(\mathrm{MPM}+d p / d x)$ and MPM with the inclusion local acceleration and phase lag (Nielsen, 2002).

\section{Meyer-Peter Muller (1948), MPM}

The predicted transport using the original form of the MPM formula is evaluated with the friction factor, $f_{2.5}$, and Shield's parameter, $\theta$, calculated based on Nielsen (1992):

$$
\begin{gathered}
\frac{q_{p}}{\sqrt{(s-1) g D^{3}}}=C\left(\theta-\theta_{c r}\right) \sqrt{\theta} \\
\theta=\frac{0.5 \rho f u^{2}}{\rho(s-1) g D} \\
f_{2.5}=\exp \left[5.5\left(\frac{2.5 D_{50}}{A_{r m s}}\right)^{0.2}-6.3\right]
\end{gathered}
$$

where $A_{r m s}=\frac{\sqrt{2}}{\omega_{p}} \sqrt{\operatorname{Var}\left\{u_{\infty}(t)\right\}}, \omega_{p}=\frac{2 \pi}{T}$ and $C=12$ are wave orbital amplitude, peak angular frequency and transport coefficient respectively. By combining Equation (4), (5) and (6), the MPM formula gives a weak grain size dependency only through the friction factor. However, for a similar velocity with varying $D$, the theory demonstrates that the MPM formulation shows a positive $q-D$ relation (Figure 4).

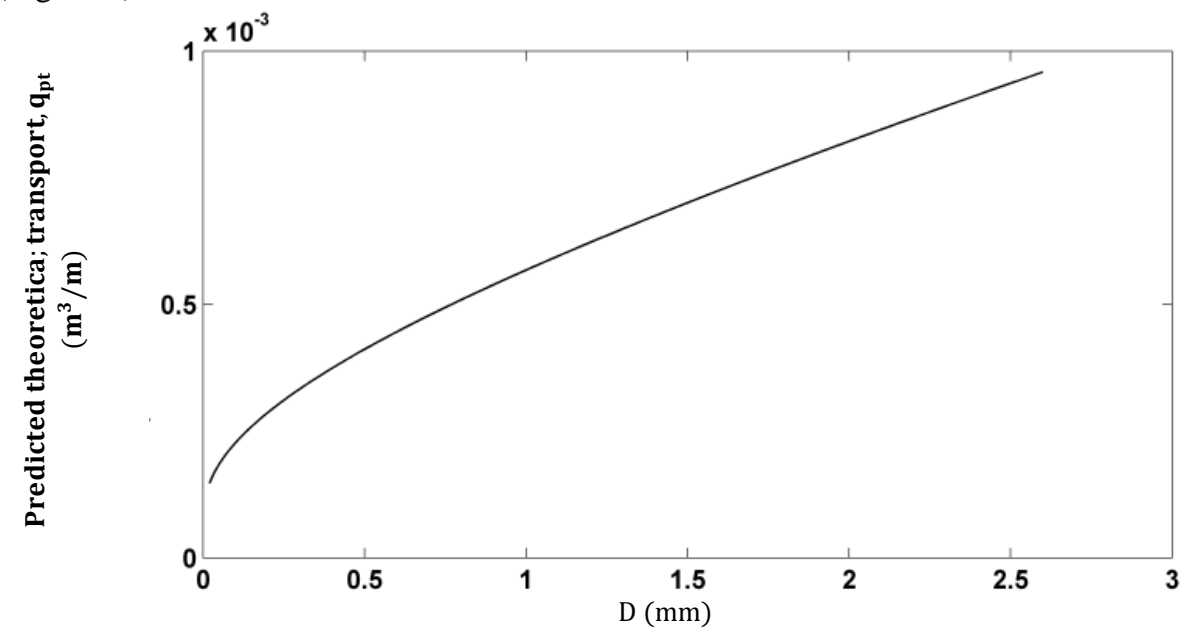

Figure 4. Predicted theoretical transport, $q_{p_{t}}$, against grain size, $D$, using MPM

The calculations are performed using the calibrated velocities and are compared with the measured data (Figure 5). In contrary to Figure 4, a negative dependency is obtained between transport and grain size. Figure 5 demonstrates that the standard MPM model underpredicts the measurements. Further, the regression lines for the horizontal bed do not pass close to the origin, which signifies errors in the estimated $\theta_{c r}$. Nevertheless, the sloping bed data have a very small $y$ intercept, less than or equal to $10^{-}$ 5 (not included in Table 4), suggesting a close prediction of $\theta_{c r}$. 
The impact of offset $y$ intercepts leads to different possible estimates of the grain size dependency. For the horizontal bed, Figure 5 indicates that transport increases with grain size for a given $q_{p}$ (i.e. positive dependency); however, the calculated $p$ value implies a negligible dependency because the gradient of the regression lines are very similar. The sloping beds on the other hand demonstrate a negative dependency from both the magnitude of the transport and the regression lines, where the calculated $p=-0.26$. This raises the question of how the dependency should be calculated, based on the slope of the regression lines, or $q_{1} / q_{2}$ for a given $q_{p}$, i.e. transport magnitude versus the transport coefficient $C$ in the MPM formulation.

Additionally, in Figure 6 the clear separation between horizontal and sloping bed data may indicate different modes of transport, as speculated earlier, and physical processes such as the grain interaction which are difficult to measure and generally unknown (e.g. Khezri and Chanson, 2012). Given that the sediment transport on the sloping beds in Figure 6 shows a negligible bed slope effect, another candidate for the difference between horizontal and sloping bed data is from the pressure gradient, $d p / d x$, explored in the next subsections.

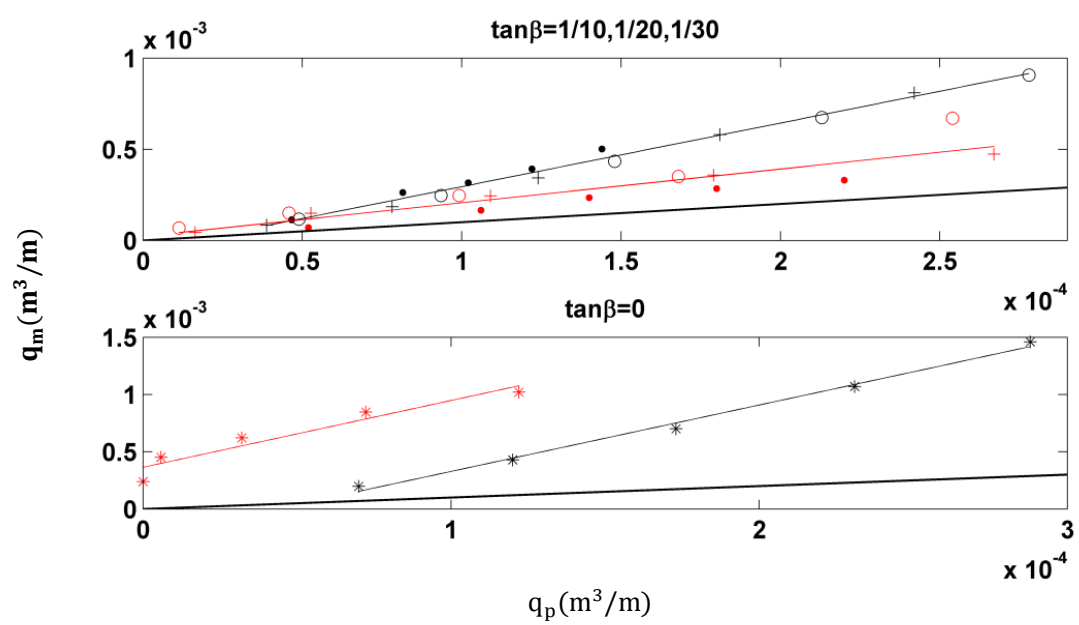

Figure 5. Measured against predicted transport, $q_{p}$, for $D_{50}=0.22 \mathrm{~mm}$ (black) and $2.65 \mathrm{~mm}$ (red). Thick solid line is $1: 1$ line.

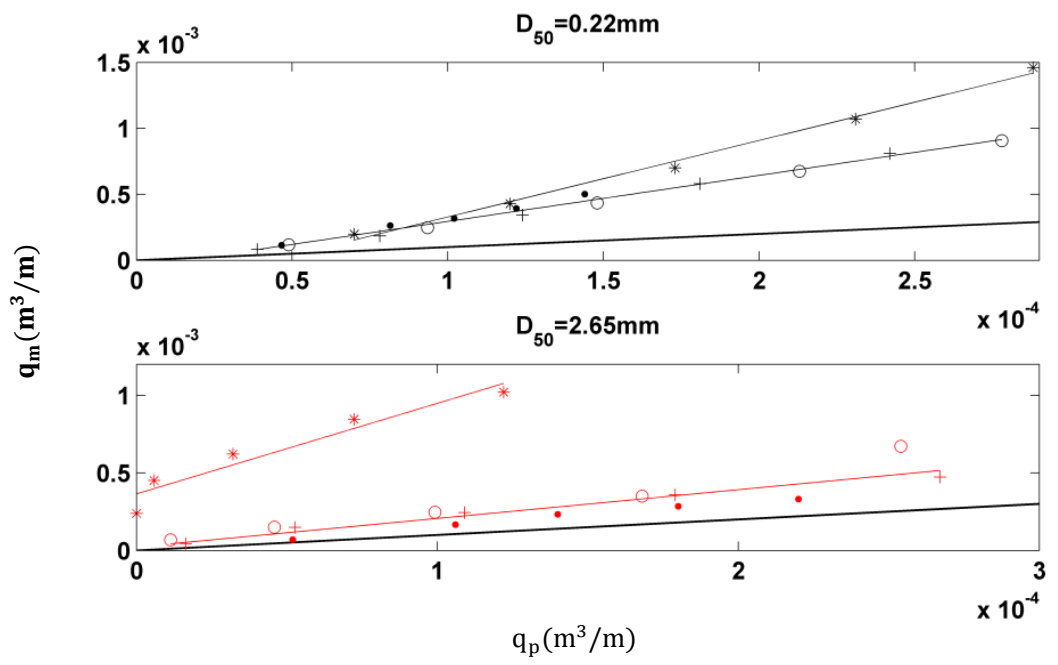

Figure 6. Measured against predicted transport, $q_{p}$, for $D_{50}=0.22 \mathrm{~mm}$ (black) and $2.65 \mathrm{~mm}$ (red) on $\tan \beta=1 / 10$ (.), 1/20 (+), 1/30 (o) and $0\left(^{*}\right)$. Thick solid line is $1: 1$ line.

\begin{tabular}{|l|l|l|}
\hline \multicolumn{3}{|c|}{ Table 4. Linear regression for $\boldsymbol{q}_{\boldsymbol{p}}$ via MPM. } \\
\hline \multicolumn{1}{|c|}{$\tan \beta$} & Linear regression equation, $y=; R^{2}$ \\
\cline { 2 - 3 } & $D_{50}=0.22 \mathrm{~mm}$ & $D_{50}=2.65 \mathrm{~mm}$ \\
\hline $1 / 10$ to $1 / 30$ & $3.49 x ; 0.99$ & $1.85 x ; 0.84$ \\
0 & $5.8 x-0.0003 ; 0.99$ & $5.83 x+0.0004 ; 0.92$ \\
\hline
\end{tabular}




\section{Meyer-Peter Muller (1948), with pressure gradient, $d p / d x$, correction.}

The sediment transport measurements under oscillatory flow (Flores and Sleath, 1998) and skewed waves (e.g. Watanabe and Sato, 2004) have supported $d p / d x$ from local acceleration, $\partial u / \partial t$, as a mechanism that enhances onshore transport. The concept was later adopted for the swash (e.g. Puleo et al., 2003, Nielsen, 2002). However, the swash simulations by Puleo et al. (2007) using total acceleration, $D u / D t$, indicate that $D u / D t$ contributes less than $22 \%$ to the onshore transport enhancement (i.e. positive $d p / d x$ ) because the swash run up flow decelerates for most of the run-up. Similarly, a recent laboratory investigation using the state of the art Bubble Image Velocimetry (Pedrozo-Acuña et al., 2011, Baldock, 2012) suggests that there is a weak correlation between local acceleration and pressure gradient in the swash zone. Therefore, instead of using Eulerian measurements of local flow acceleration, the present study used the surface elevation, $\eta$, to infer pressure gradient (i.e. $d p / d x=-\rho(d u / d t)=\rho g(d \eta / d x)$ ). The formula is given as (Nielsen, 1992):

$$
\theta_{P G}=\frac{0.5 \rho f u^{2}+\rho g(d \eta / d x) D}{\rho(s-1) g D}
$$

The $d p / d x$ term is calculated using a hydrostatic assumption (Baldock and Hughes, 2006) inferred from the measured $\eta$ between 2 consecutive sensors (i.e. $d p / d x=\rho g\left(\left(\eta_{1}-\eta_{2}\right) / d x\right)$ ) as depicted in Figure 7. $d p / d x$ is taken to be negative if dipping seaward toward the reservoir (i.e. generating a reduction in bed shear stress, $\tau$ ) and vice versa.

Figure 8 illustrates the typical time series of measured depth, $h$, and the associated modeled depth averaged horizontal velocity, $\bar{u}$ for tests with $d_{o}=0.2 \mathrm{~m}$. The maximum $\bar{u}$ and $h$ are smaller and larger respectively for the coarse sand in comparison to fine sand and also the uprush flow duration increases for the milder bed slopes. Figure 9 illustrates the influence of $\rho g(d \eta / d x) D$ for the fine and coarse grains where $d \eta / d x$ is negative for the sloping beds most of the time. $F_{p} / F_{d}=\rho g(d \eta / d x) D /$ $0.5 \rho f u^{2}$ in Figure 9 is calculated for $\theta_{P G}>\theta_{c r}$ which limits the influence of $d p / d x$ in sediment transport calculation for the sloping bed. A kink at the end of $F_{p} / F_{d}$ for the coarse sand on $\tan \beta=1 / 30$ is caused by a positive $d \eta / d x$ at the end of the $\theta_{P G}$ calculation. The increasing ratio of $F_{p} / F_{d}$ indicates an increase in the influence of $d p / d x$ towards the end of the flow as the flow slows down.

A similar example is also given for the horizontal bed (Figure 10 and Figure 11), for initial bore heights/dam depths, $d_{o}=0.08 \mathrm{~m}$ and $0.14 \mathrm{~m}$ respectively. Contrary to the sloping beds, it is found that the pressure gradient is positive most of the time and the influence of the pressure gradient on the coarse sand is much greater. The positive pressure gradient is more pronounced for coarse sand due to the slower moving wave tip relative to the upstream flow, particularly for $d_{o}=0.08 \mathrm{~m}$. Unlike the coarse sand, the pressure gradient effect is very mild for both $d_{o}$ for the fine sand.

On average, the total contribution from the pressure gradient reduces $q_{p}$ for the sloping beds by $4 \%$ (fine sand) to $18 \%$ (coarse sand) and increases $q_{p}$ for the horizontal bed by $1 \%$ (fine sand) to two orders of magnitude (coarse sand). In fact, the incorporation of $d p / d x$ has improved the transport prediction tremendously for the coarse sand on horizontal bed from $q_{m} \approx 5.8 q_{p}$ to $q_{m} \approx 2.4 q_{p}$ whilst bringing the sloping and horizontal beds data much closer together, reducing the scattered data points as illustrated in Figure 12. This demonstrates the importance of the pressure gradient in the sediment transport calculations on the horizontal bed, although the impact is small for fine sand because of the grain size scaling in the pressure gradient stress term (i.e. $\rho g(d \eta / d x) D$ ). Instead, it is possible that $D$ can be replaced by the thickness of the sheet flow layer since it is well known that the sheet flow sediment moves as a thick dense layer (e.g. Sumer et al., 1996), but this requires more knowledge on the dynamic of this layer with different flow condition and grain sizes.

The improved $q_{p}$ on the horizontal bed reduces the slope of the regression line (Table 5) and changes the grain size dependency to negative, $p \approx-0.3$. However, there are no changes in the dependency for the sloping beds, due to the limited influence of $d p / d x$ in the sediment transport calculations.

On a separate point, if using $d u / d t, u$ starts from the maximum velocity which is approximately the wave's tip celerity (i.e. $u_{\max } \approx c_{\text {tip }}$ ), onwards. If the calculation starts beforehand, this will results in a large imaginary acceleration at the start of the flow. Additionally, using $d u / d t$ as a proxy to $d p / d x$ can be erroneous in the swash zone because often $u \partial u / \partial x \gg \partial u / \partial t$ (Puleo et al., 2007) and 
$\partial u / \partial t$ is always negative while $d \eta / d x$ varies (Baldock and Hughes, 2006), as illustrated in Figure 9 and Figure 11.

Datum, $\mathrm{z}=0$

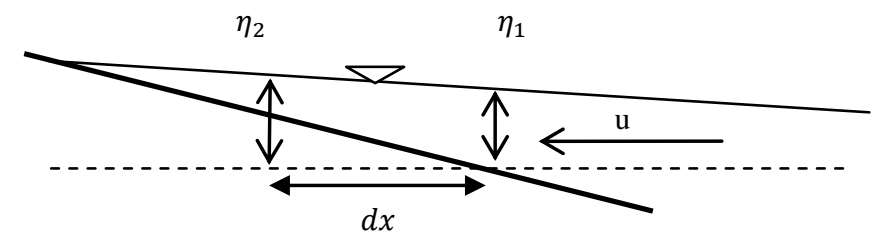

Figure 7. Pressure gradient convention using piezometric head for the present study.
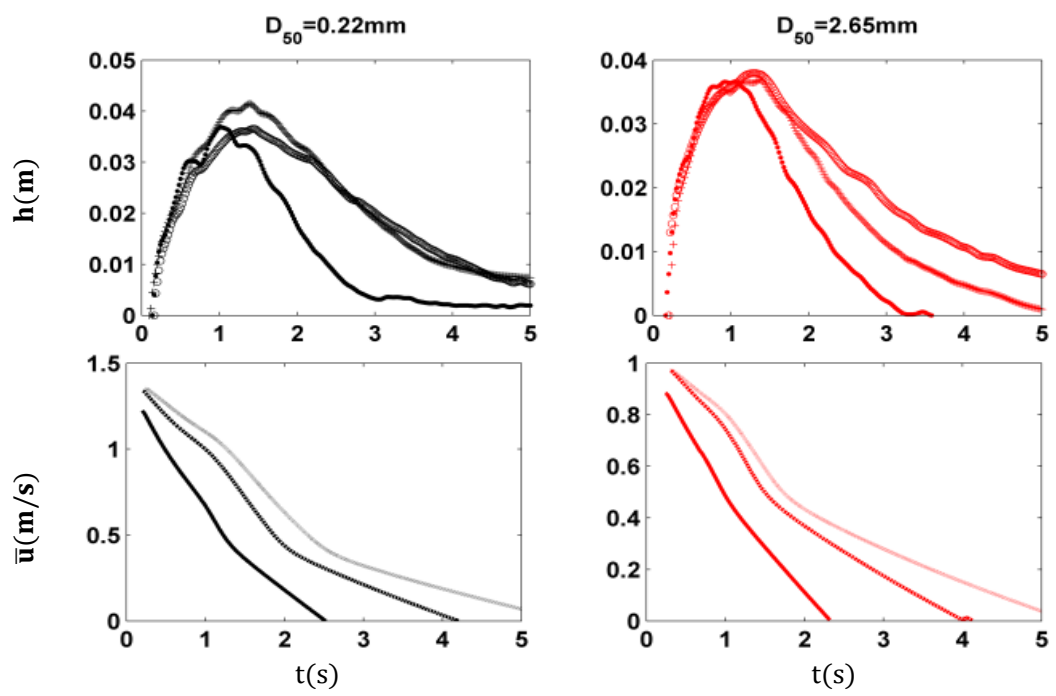

Figure 8. Measured (symbols) flow depth, $h$, and modelled (lines) average horizontal velocity, $\bar{u}$, at $x=1.955 \mathrm{~m}$ downstream of the gate for uprush. $D_{50}=0.25 \mathrm{~m}$ on $\tan \beta=1 / 10(. ;-), D_{50}=0.20 \mathrm{~mm}$ on $\tan \beta=1 / 20(+;---)$ and $D_{50}=0.18 \mathrm{~mm}$ on $\tan \beta=1 / 30(0 ; \ldots)$.
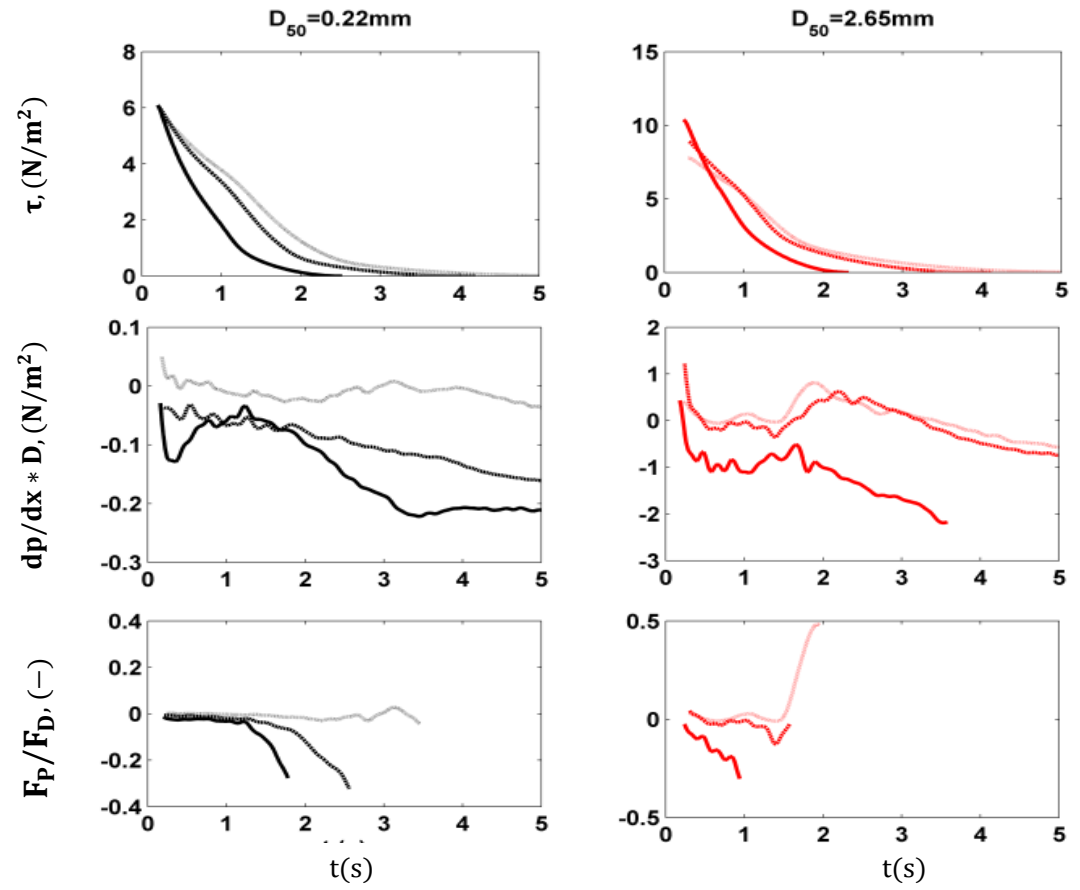

Figure 9. Stress and pressure gradient contribution to sediment transport model. $F_{p} / F_{d}=d p / d x D / 0.5 \rho f u^{2}$ for uprush. $d_{o}=0.25 \mathrm{~m}$ on $\tan \beta=1 / 10(-), d_{o}=0.20 \mathrm{~m}$ on $\tan \beta=1 / 20(--)$ and $d_{o}=0.18 \mathrm{~m}$ on $\tan \beta=1 / 30(\ldots)$. 

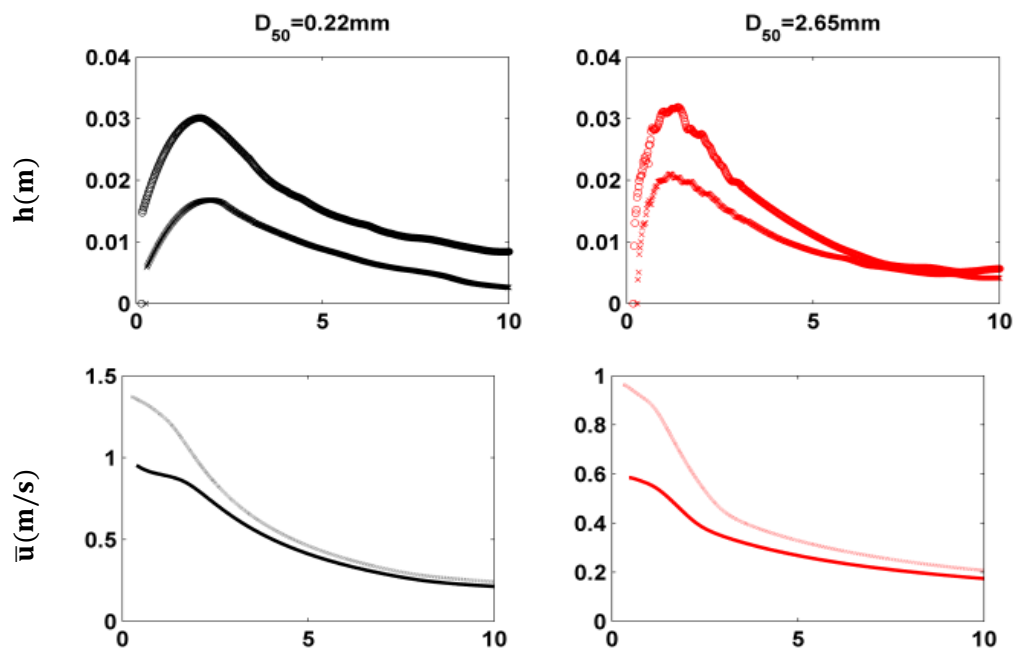

$\mathrm{t}(\mathrm{s})$

$t(s)$

Figure 10. Measured (symbols) flow depth, $h$, and modelled (lines) average horizontal velocity, $\bar{u}$, at $x=1.955 \mathrm{~m}$ downstream of the gate for horizontal bed. $d_{o}=0.08 \mathrm{~m}(\mathrm{x} ;-), d_{o}=0.14 \mathrm{~m}$ on $\tan \beta=1 / 20(0 ; \ldots)$.
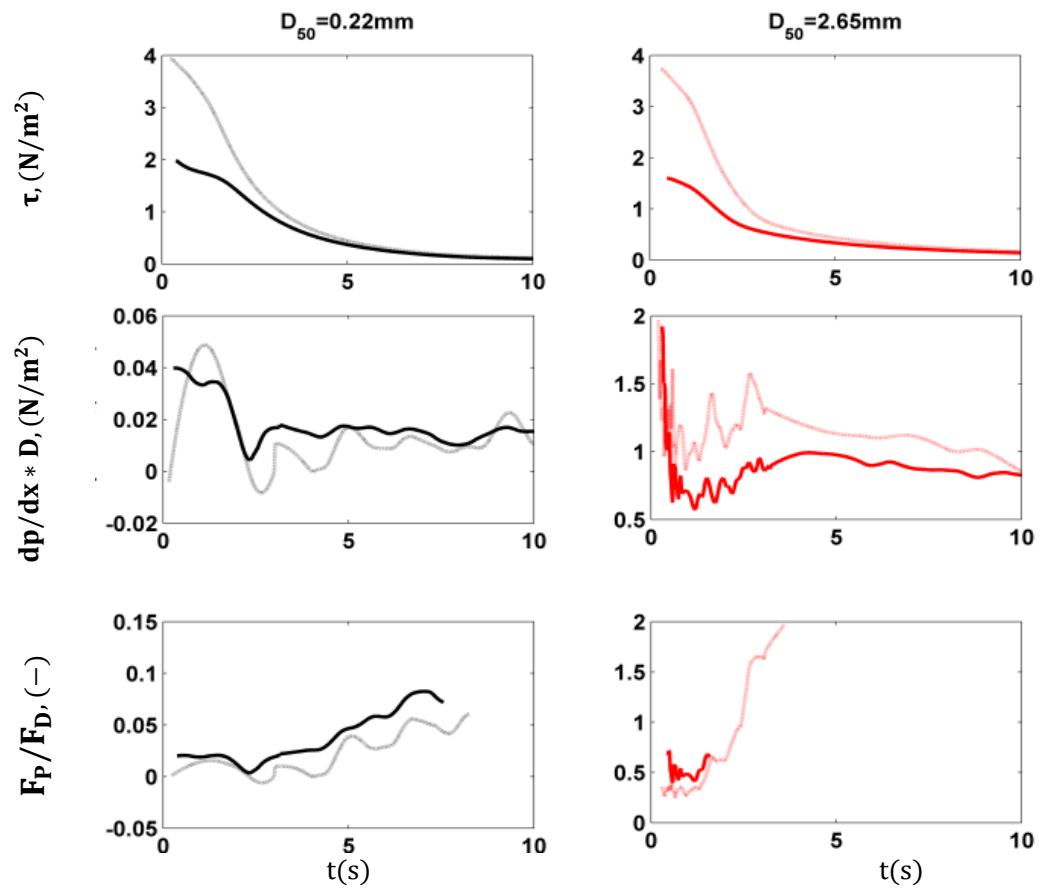

Figure 11. Ratio of stress, pressure gradient contribution to drag, $F_{p} / F_{d}=d p / d x D / 0.5 \rho f u^{2}$ for horizontal bed. $d_{o}=0.08 \mathrm{~m}$ on (-) and $d_{o}=0.14 \mathrm{~m}(\ldots)$. 


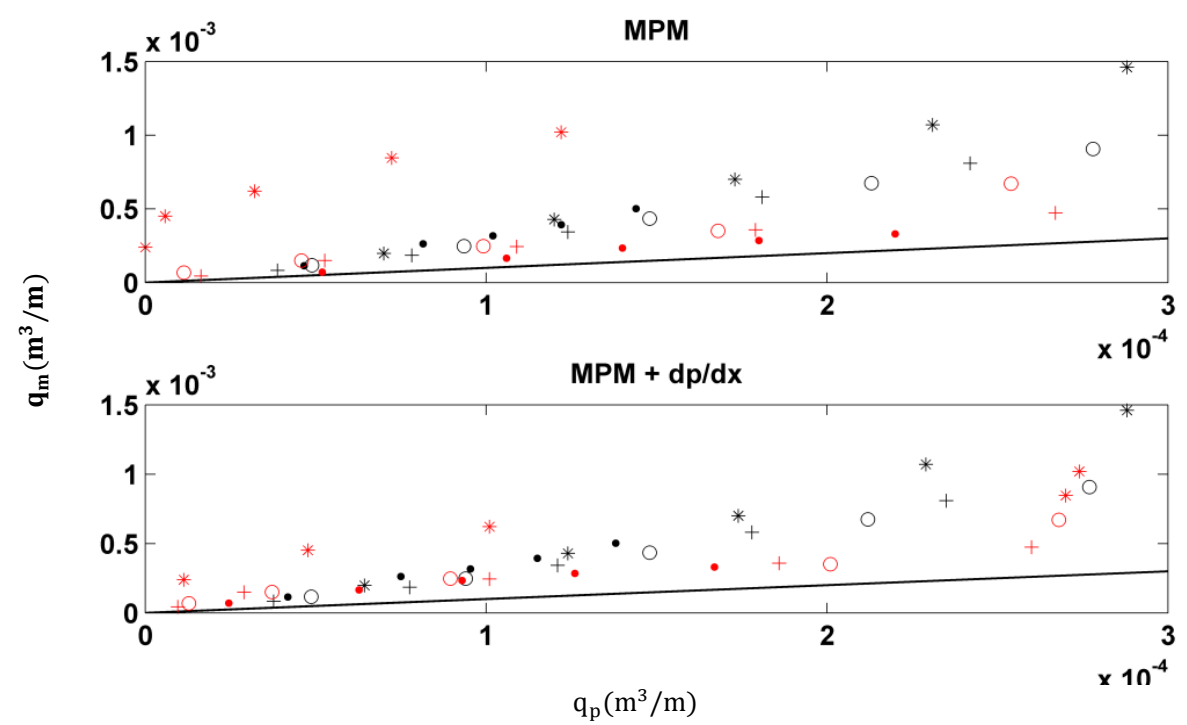

Figure 12. Measured against predicted transport, $q_{p}$, using MPM (top) and MPM with $d p / d x$ (bottom) for $D_{50}=0.22 \mathrm{~mm}$ (black) and 2.65mm (red) on $\tan \beta=1 / 10(),. 1 / 20(+), 1 / 30$ (o) and $0\left(^{\star}\right)$.Solid line is 1:1 line.

\begin{tabular}{|l|l|l|}
\hline \multicolumn{3}{|c|}{ Table 5. Linear regression for $\boldsymbol{q}_{\boldsymbol{p}}$ via MPM+dp/dx . } \\
\hline \multirow{2}{*}{$\tan \beta$} & Linear regression equation, $y=; R^{2}$ \\
\cline { 2 - 3 } & $D_{50}=0.22 \mathrm{~mm}$ & $D_{50}=2.65 \mathrm{~mm}$ \\
\hline $1 / 10$ to $1 / 30$ & $3.48 \mathrm{x} ; 0.98$ & $1.84 \mathrm{x} ; 0.92$ \\
0 & $5.73 \mathrm{x}-0.0002 ; 0.99$ & $2.4 \mathrm{x}+0.0003 ; 0.92$ \\
\hline
\end{tabular}

Nielsen (2002)

Nielsen (2006, 2002) and Nielsen and Callaghan (2003) have suggested a modified version of the MPM formula that incorporate the pressure gradient in the form of local acceleration and additional phase lag, $\varphi_{\tau}$, between velocity and sediment concentration (i.e. bed shear stress and instantaneous transport rates). The phase lag is needed to take into account the differing fluid acceleration in asymmetric waves. The formula generates the sediment mobilizing velocity in the form of:

$$
\begin{gathered}
u_{\theta}(t)=\sqrt{\frac{1}{2} f_{2.5}}\left(\cos \varphi_{\tau} u+\sin \varphi_{\tau} \frac{d u / d t}{\omega}\right) \\
\theta(t)=\frac{\tau_{b}}{\rho(s-1) g D_{50}}=\frac{u_{\theta}^{2}(t)}{(s-1) g D_{50}}
\end{gathered}
$$

The value of $\varphi_{\tau}$ varies between $37.5^{\circ}$ and $51^{\circ}$ (Nielsen, 2002, Nielsen and Callaghan, 2003). In the present calculation, $\varphi_{\tau}=45^{\circ}$ are used based on the maximum $\varphi_{\tau}$ obtained in Nielsen (2002) using the swash data of Masselink and Hughes (1998). If $\varphi_{\tau}$ is set to $0^{\circ}$ (transport is drag dominated), then Equation (9) reduces to Equation (5).

Applying this formula resulted in the extreme underprediction of the total transport, by an order of magnitude for fine sand and by two orders of magnitude for coarse sand on the sloping beds (Figure 13 and Table 6). Consequently, 4 out of $15(27 \%)$ tests for the sloping bed and all the data points on the horizontal bed give $q_{p}=0$ as $\theta \ll \theta_{c r}$. These tests have been excluded in Figure 13 for better regression estimates.

The reason for $q_{p}=0$ is because $d u / d t$ is negative, thus reducing the representative velocity component, $\cos \varphi_{\tau} u+\sin \varphi_{\tau}(d u / d t) / \omega$ (Figure 14) by approximately 3 times, $\theta(\mathrm{t})$ (Figure 15), and $q(t)$ (Figure 16) correspondingly. Additionally, this demonstrates the importance of using $d p / d x$ in swash sediment transport calculations, instead of $d u / d t$.

The transport prediction for coarse sand shows two different regression lines where the prediction on $\tan \beta=1 / 10$ (dots) sit on the same level as the predicted transport for fine sands, whereas the 
transport prediction for $\tan \beta=1 / 20$ and $1 / 30$ sit above the rest of the data. The calculated $p$ values between fine and coarse sand on $\tan \beta=1 / 10$ and between fine and coarse sand on $\tan \beta=1 / 20$ and $1 / 30$ are 0.11 and 0.58 respectively, as the slope of the regression lines for the coarse sand are steeper than the fine sand.

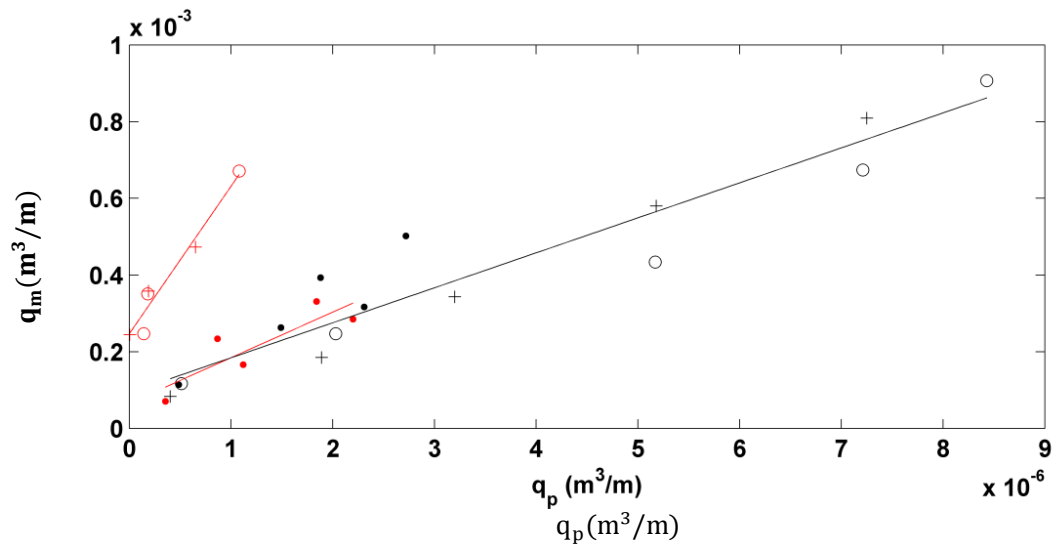

Figure 13. Measured against predicted transport, $q_{p}$, for $D_{50}=0.22 \mathrm{~mm}$ (black) and $2.65 \mathrm{~mm}$ (red) on $\tan \beta=1 / 10(\cdot), 1 / 20(+), 1 / 30$ (0) and $0\left(^{*}\right)$ using Nielsen (2002).

\begin{tabular}{|c|l|l|}
\hline \multicolumn{3}{|c|}{ Table 6. Linear regression for $\boldsymbol{q}_{\boldsymbol{p}}$ via Nielsen (2002). } \\
\hline \multirow{2}{*}{$\tan \beta$} & \multicolumn{2}{|c|}{ Linear regression equation, $y=; R^{2}$} \\
\cline { 2 - 3 } & $D_{50}=0.22 \mathrm{~mm}$ & $D_{50}=2.65 \mathrm{~mm}$ \\
\hline $1 / 10$ to $1 / 30$ & $91.22 \mathrm{x} ; 0.91$ & $118.91 \mathrm{x} ; 0.75$ \\
$1 / 20$ and $1 / 30$ & - & $384.75 \mathrm{x}+0.0002 ; 0.95$ \\
\hline
\end{tabular}

for $\tan \beta=1 / 10$ only

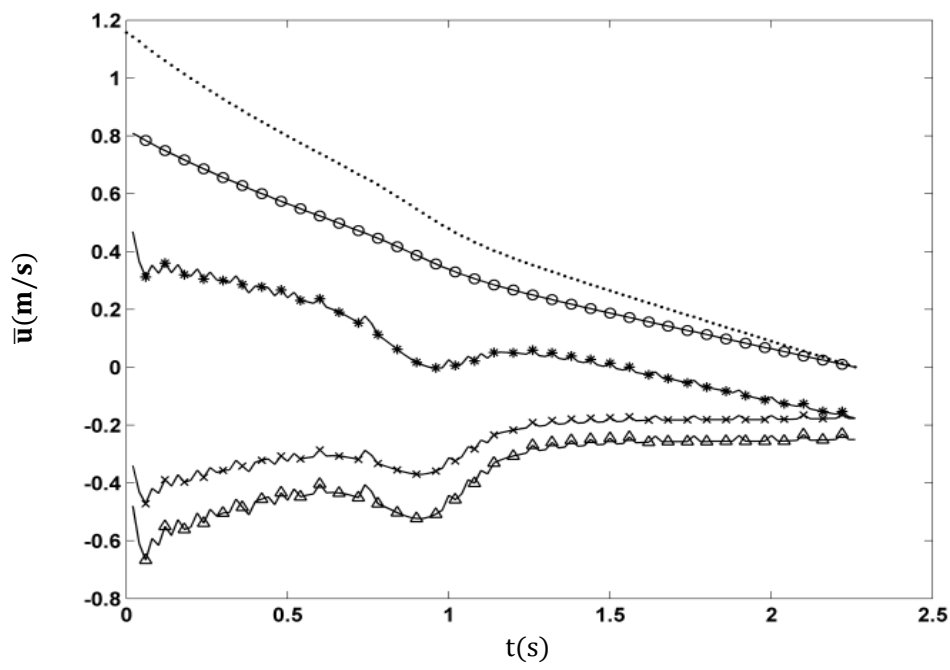

Figure 14. Instantaneous velocity components for uprush on $\tan \beta=1 / 10, d_{o}=0.24 \mathrm{~m}$ and $D_{50}=0.22 \mathrm{~mm}$. Modelled $u(\cdot), \cos \varphi_{\tau} u(0), \cos \varphi_{\tau} u+\sin \varphi_{\tau}(d u / d t) / \omega\left({ }^{*}\right), \sin \varphi_{\tau}(d u / d t) / \omega(\mathrm{x})$, and $(d u / d t) / \omega(\Delta)$. 


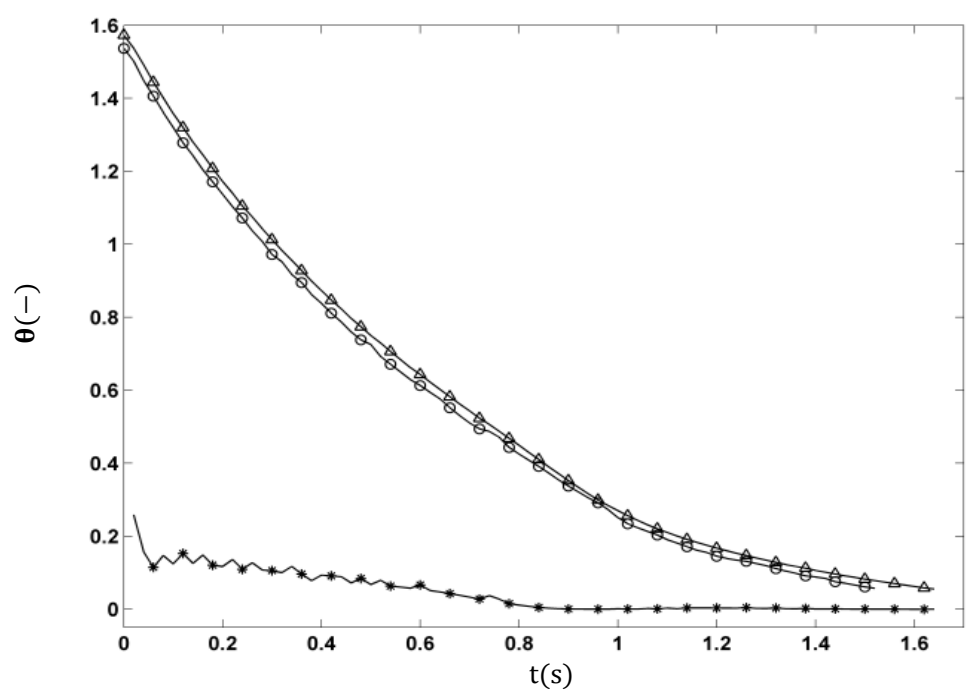

Figure 15. Instantaneous $\theta$ for uprush $\tan \beta=1 / 10, d_{o}=0.24 \mathrm{~m}$ and $D_{50}=0.22 \mathrm{~mm} . \tau / \rho(s-1) g D(\Delta),(\tau-$ $\rho g d \eta / d x D) / \rho(s-1) g D(0)$, and Equation (9) (*).

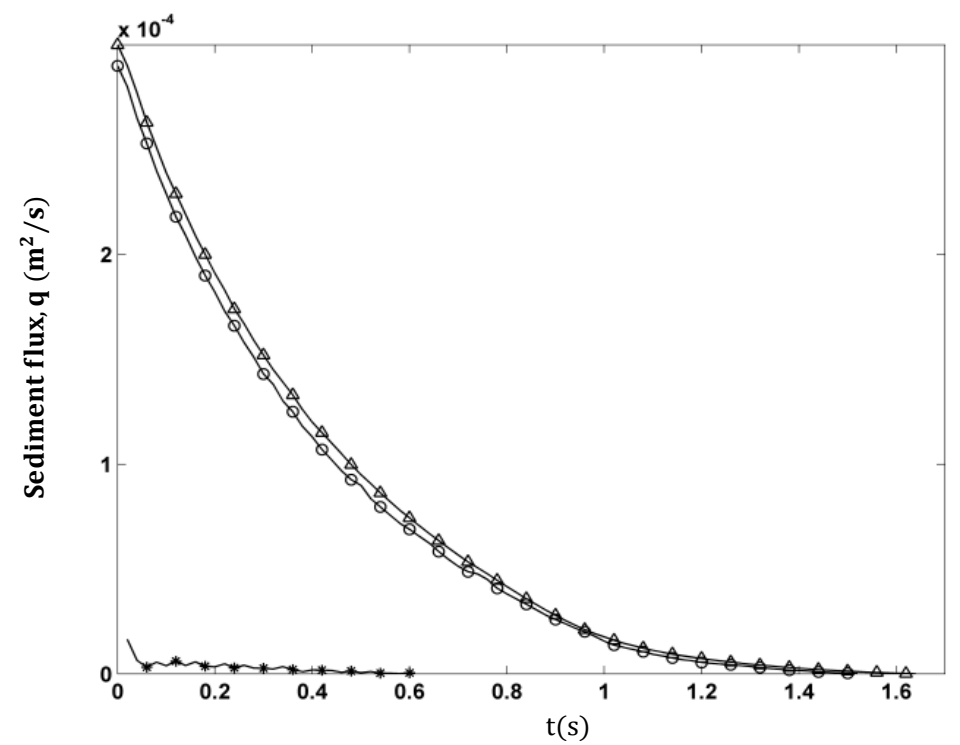

Figure 16. Calculated sediment flux for uprush on $\tan \beta=1 / 10, d_{o}=0.24 \mathrm{~m}$ and $D_{50}=0.22 \mathrm{~mm}$. See prior figure for legend.

\section{Proximity of the predicted transport to the measured transport}

The Brier Skill Score, BSS (Van Rijn et al., 2003), given in Equation (10) below is used to estimate the proximity of the predicted to the measured transport via the different methods. The formula gives 1 for a perfect prediction and 0 for no skill. The BSS for each method of predictions are tabulated in Table 7. The highest score, bold values in Table 7, indicate that the best method for fine sand is using MPM but for coarse sand on horizontal bed MPM $+d p / d x$ gives better prediction. Nevertheless, the difference in the score between MPM and MPM $+d p / d x$ is small, but certainly larger for coarser sediment. Thus, it is suggested that MPM $+d p / d x$ is adopted as a general transport. Conversely, very poor predictions are obtained using Nielsen (2002), particularly because of the use of local acceleration in the stress calculation.

$$
B S S=1-\frac{\sum\left[\left(q_{m}-q_{p}\right) / q_{m}\right]^{2}}{n}
$$




\begin{tabular}{|l|l|l|l|l|}
\hline \multicolumn{6}{|l|}{ Table 7. BSS of the predicted transport $\left.\mathbf{~ m}^{\mathbf{3}} / \mathbf{m}\right)$. } \\
\hline BSS & $D_{50}(\mathrm{~mm})$ & MPM $(C=12)$ & MPM $+d p / d x$ & Nielsen (2002) \\
& & & & \\
\hline Uprush & 0.22 & $\mathbf{0 . 5 8}$ & 0.56 & 0.02 \\
(Sloping beds) & 2.65 & $\mathbf{0 . 7 1}$ & 0.60 & 0.01 \\
\hline Horizontal bed & 0.22 & $\mathbf{0 . 4 5}$ & 0.44 & 0.00 \\
& 2.65 & 0.1 & $\mathbf{0 . 3 2}$ & 0.00 \\
\hline
\end{tabular}

\section{$p$ Values}

In order to maintain the reliability of the $p$ values, only the slopes of the regression lines with $R^{2}>0.8$ are chosen. This excludes $q_{p}$ for coarse sand via Nielsen (2002) on $\tan \beta=1 / 10$. The overall $p$ values deduced from the above plots are summarized in Figure 17. The grain size dependency for different parameters indicates:

- $d_{o}$ : Inverse $q-D$ dependency for the uprush and horizontal bed, reaching $p \approx-0.22$. This implicitly reflects the influence of friction on flow and hence the transport.

- $\int \bar{u}^{3} d t$ : Positive $q-D$ dependency for the uprush and horizontal bed, up to $p \approx 0.26$, where $q$ increases as $D$ increases. This is associated with the monotonically decreasing velocity and overtopping duration as $D_{50}$ increases.

- $q_{p}$ : Inverse $q-D$ dependency with maximum $p \approx-0.35$ for the horizontal bed via MPM with incorporation of $d p / d x$. However, the uprush dependency does not change with and without $d p / d x$ due to the limited influence of $d p / d x D$ when $\theta_{P G}>\theta_{c r}$. However, the transport prediction using Nielsen (2002) indicates positive dependency of $p \approx 0.58$.

The average $p$ value is found to be narrow ranged, $0.5<p<-0.5$.

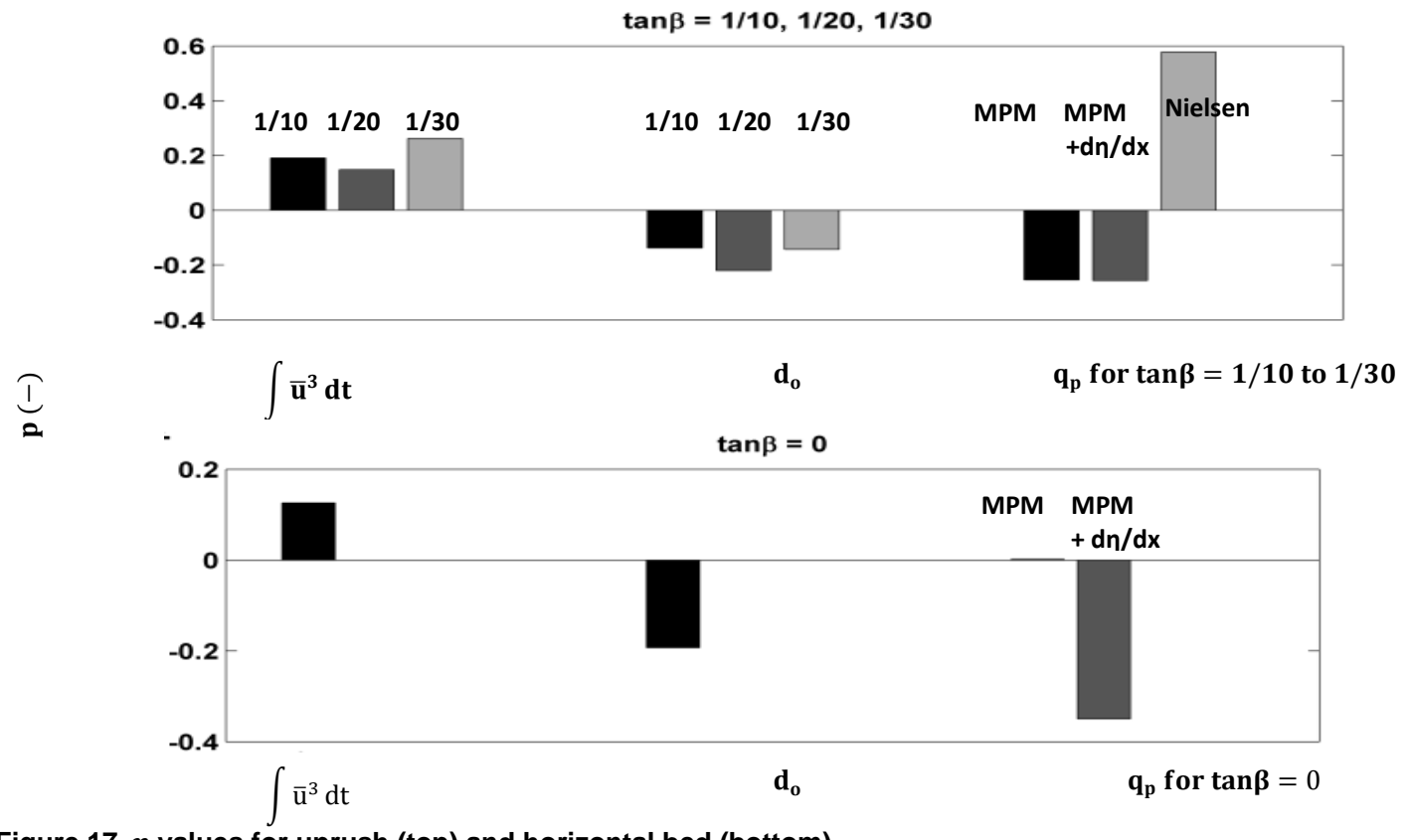

Figure 17. $p$ values for uprush (top) and horizontal bed (bottom).

\section{Conclusions}

New sediment transport experiments have investigated the influence of grain size and pressure gradients on unsteady sediment transport, with application to swash zone flows. The $q-D$ dependencies are deduced from the slope of linear regression lines for the initial dam depth, $d_{o}$, time integrated depth averaged velocity, $\int \bar{u}^{3} d t$, and predicted transport, $q_{p}$, using the Meyer-Peter Muller (1948) transport model. The data shows different dependencies are obtained depending on the chosen parameters. Overall, negative dependencies $(p<0)$ are obtained for $d_{o}$ and $q_{p}$ while positive dependencies $(p>0)$ are obtained for $\int \bar{u}^{3} d t$. This denotes that a given $d_{o}$ and $q_{p}$ transports less 
sediment of larger grain than of smaller grain as opposed to $\int \bar{u}^{3} d t$.The $p$ value is found to be narrow ranged, $0.5 \leq p \leq-0.5$.

The discernible difference in the measured and predicted transport between horizontal and sloping beds may illuminate different modes of transport and incorporation of a pressure gradient correction in the transport calculation has greatly improved the transport predictions on the horizontal bed, whilst bringing the data on horizontal and sloping beds closer. The improved prediction is due to a stronger positive pressure gradient influence on horizontal bed in contrast to the sloping beds. In general, pressure gradient is found to be negative on the sloping beds, consistent with field measurement (Baldock and Hughes, 2006), and positive on the horizontal bed.

Moreover, the measured and predicted transport on sloping beds does not show a significant bed slope effect at least for the velocities tested here. On average, the total contribution of pressure gradient reduces the transport prediction over the sloping beds by $4 \%$ (fine sand) to $18 \%$ (coarse sand) and increases $q_{p}$ over the horizontal bed by $1 \%$ (fine sand) to two orders of magnitude (coarse sand). It is suggested that future general swash sediment transport models should incorporate the grain size effect, partly through the pressure gradient. However, the importance of this correction will mainly occur for large grain sizes and for positive pressure gradients, i.e. in the backwash.

In term of proximity to $q_{m}$ (i.e. $q_{m} \approx q_{p}$ ), the best prediction method for fine sand is MPM, followed closely by MPM $+d p / d x$. MPM $+d p / d x$ gives better predictions for coarse sand on the horizontal bed. Poor predictions are obtained using Nielsen (2002), because the negative value of $d u / d t$ results in the reduction of stress and total transport, rather than an increase.

\section{REFERENCES}

Bagnold, R. A. 1956. The flow of cohesionless grains in fluids. Philosophical Transactions of the Royal Society of London. Series A, Mathematical and Physical Sciences, 249, 235-297.

Bagnold, R. A. 1980. An Empirical Correlation of Bedload Transport Rates in Flumes and Natural Rivers. Proceedings of the Royal Society of London. Series A, Mathematical and Physical Sciences, 372, 453-473.

Bagnold, R. A. 1986. Transport of solids by natural water flow: evidence for a worldwide correlation. Proceedings of the Royal Society of London. Series A, Mathematical and Physical Sciences, 405, 369-374.

Baldock, T., Hughes, M., Day, K. \& Louys, J. 2005. Swash overtopping and sediment overwash on a truncated beach. Coastal Engineering, 52, 633-645.

Baldock, T. E. 2012. Discussion of "Laboratory investigation of pressure gradients induced by plunging breakers", by Pedrozo-Acuña et al. Coastal Engineering, 66, 1-2.

Baldock, T. E. \& Hughes, M. G. 2006. Field observations of instantaneous water slopes and horizontal pressure gradients in the swash-zone. Continental Shelf Research, 26, 574-588.

Barnes, M. \& Baldock, T. E. 2007. Direct bed shear stress measurements in laboratory swash. Journal of Coastal Research, 50, 641-645.

Barnes, M. P. 2009. Measurement and modelling of swash zone bed shear stress. PhD Thesis PhD Thesis, University of Queensland.

Blenkinsopp, C. E., Turner, I. L., Masselink, G. \& Russell, P. E. 2010. Validation of volume continuity method for estimation of cross-shore swash flow velocity. Coastal Engineering, 57, 953-958.

Carrigy, M. A. 1970. Experiments on the angles of repose of granular materials. Sedimentology, 14, 147-158.

Del Valle, R., Medina, R. \& Losada, M. 1993. Dependence of coefficient K on grain size. Journal of Waterway, Port, Coastal and Ocean Engineering, 119, 568.

Elfrink, B. \& Baldock, T. 2002. Hydrodynamics and sediment transport in the swash zone: a review and perspectives. Coastal Engineering, 45, 149-167.

Flores, N. Z. \& Sleath, J. F. A. 1998. Mobile layer in oscillatory sheet flow. Journal of Geophysical Research, 103, 12783-12793.

Fredsoe, J. \& Deigaard, R. 1992. Mechanics of coastal sediment transport, Singapore, World Scientific.

Friedman, S. P. \& Robinson, D. A. 2002. Particle shape characterization using angle of repose measurements for predicting the effective permittivity and electrical conductivity of saturated granular media. Water Resources Research, 38, 1236. 
Hughes, M. G. \& Baldock, T. E. 2004. Eulerian flow velocities in the swash zone: field data and model predictions. Journal of Geophysical Research, 109, C08009.

Khezri, N. \& Chanson, H. 2012. Inception of bed load motion beneath a bore. Geomorphology, 153154, 39-47.

King, D. 2005. Influence of grain size on sediment transport rates with emphasis on the total longshore rate, Coastal Hydraulics Lab Development Center Vicksburg, US ARMY CORPS OF ENGINEERS, V., MS, ERDC/CHL CHETN-II-48.

Martin, Y. \& Church, M. 2000. Re-examination of Bagnold's empirical bedload formulae. Earth Surface Processes and Landforms, 25, 1011-1024.

Masselink, G. \& Hughes, M. 1998. Field investigation of sediment transport in the swash zone. Continental Shelf Research, 18, 1179-1199.

Masselink, G. \& Russell, P. 2006. Flow velocities, sediment transport and morphological change in the swash zone of two contrasting beaches. Marine Geology, 227, 227-240.

Meyer-Peter, E. \& Müller, R. Year. Formulas for bed-load transport. In: Proceedings 2nd International IAHR Congress, 1948 Stockholm, Sweden. 39-64.

Miller, R. L. \& Byrne, R. J. 1966. The angle of repose for a single grain on a fixed rough bed. Sedimentology, 6, 303-314.

Nielsen, P. 1992. Coastal bottom boundary layers and sediment transport, World Scientific Pub Co Inc.

Nielsen, P. 2002. Shear stress and sediment transport calculations for swash zone modelling. Coastal Engineering, 45, 53-60.

Nielsen, P. 2006. Sheet flow sediment transport under waves with acceleration skewness and boundary layer streaming. Coastal Engineering, 53, 749-758.

Nielsen, P. \& Callaghan, D. P. 2003. Shear stress and sediment transport calculations for sheet flow under waves. Coastal Engineering, 47, 347-354.

O'Donoghue, T., Pokrajac, D. \& Hondebrink, L. J. 2010. Laboratory and numerical study of dam break-generated swash on impermeable slopes. Coastal Engineering, 57, 513-530.

O'Donoghue, T. \& Wright, S. 2004. Flow tunnel measurements of velocities and sand flux in oscillatory sheet flow for well-sorted and graded sands. Coastal Engineering, 51, 1163-1184.

Pedrozo-Acuña, A., de Alegría-Arzaburu, A. R., Torres-Freyermuth, A., Mendoza, E. \& Silva, R. 2011. Laboratory investigation of pressure gradients induced by plunging breakers. Coastal Engineering, 58, 722-738.

Puleo, J. A., Farhadzadeh, A. \& Kobayashi, N. 2007. Numerical simulation of swash zone fluid accelerations. Journal of Geophysical Research, 112, C07007.

Puleo, J. A., Holland, K. T., Plant, N. G., Slinn, D. N. \& Hanes, D. M. 2003. Fluid acceleration effects on suspended sediment transport in the swash zone. Journal of Geophysical Research, 108, 14-1.

Ribberink, J. S. \& Al-Salem, A. A. 1995. Sheet flow and suspension of sand in oscillatory boundary layers. Coastal Engineering, 25, 205-225.

Shields, A. 1936. Application of similarity principles and turbulence research to bed-load movement.

Sumer, B. M., Kozakiewicz, A., Fredsoe, J. \& Deigaard, R. 1996. Velocity and concentration profiles in sheet-flow layer of movable bed. Journal of Hydraulic Engineering, 122, 549-558.

Van Rijn, L. 1993. Principles of sediment transport in rivers, estuaries, and coastal seas, Aqua publications.

Van Rijn, L., Walstra, D., Grasmeijer, B., Sutherland, J., Pan, S. \& Sierra, J. 2003. The predictability of cross-shore bed evolution of sandy beaches at the time scale of storms and seasons using process-based profile models. Coastal Engineering, 47, 295-327.

van Rijn, L. C., Walstra, D. J. R. \& van Ormondt, M. 2007. Unified view of sediment transport by currents and waves. IV: Application of morphodynamic model. Journal of Hydraulic Engineering, 133, 776.

Watanabe, A. \& Sato, S. Year. A sheet-flow transport rate formula for asymmetric forward-leaning waves and currents. In: Proceedings 29th International Conference on Coastal Engineering, 2004. ASCE, 1703-1714. 